Orbis Tertius, vol. XXVI, $n^{\circ}$ 33, e189, mayo-octubre 2021. ISSN 1851-7811

Universidad Nacional de La Plata

Facultad de Humanidades y Ciencias de la Educación

Centro de Estudios de Teoría y Crítica Literaria

\title{
Unamuno, Borges y la música. De la paradoja antimodernista al equilibrio simbolista
}

\author{
Unamuno, Borges and music. From the anti-modernist paradox to the symbolist \\ balance
}

\author{
iD María Paula Cantero \\ paulacantero@usal.es \\ Universidad de Salamanca, España
}

Recepción: 22 Febrero 2021

Aprobación: 21 Abril 2021

Publicación: 03 Mayo 2021

Cita sugerida: Cantero, M. P. (2021). Unamuno, Borges y la música. De la paradoja antimodernista al equilibrio simbolista. Orbis Tertius, 26(33), e189. https://doi.org/10.24215/18517811e189

\begin{abstract}
Resumen: De todos los aspectos que comparten Borges y Unamuno, este estudio hace hincapié en la concepción musical de su poesía. Unamuno ha sido siempre un autor difícil de catalogar, por eso la crítica lo ha señalado como un autor simbolista tanto como antimodernista. Por su parte, Borges ha mostrado una postura crítica ante sus contemporáneos modernistas, así como ante la obra de Unamuno, pero su poética coincide también con las teorías simbolistas. La particular relación que la poesía de ambos escritores ha establecido con la música nos permite ligarlos a ambos movimientos. Así, es posible ver una evolución en su obra poética, que es paralela a su vida.
\end{abstract}

Palabras clave: Unamuno, Borges, Poesía, Música, Modernismo.

\begin{abstract}
From the wide range of features that both Borges and Unamuno share, this article is focused on the musical concept of their poetry. It has always been difficult to categorize an author such as Unamuno, which is why critics refer to him both as an anti-modernist and as a symbolist writer. In turn, Borges has shown a critical regard for his modernist contemporaries, as well as for Unamuno's work. However, his poetics also matches symbolist theories. The special bond between both writers' poetry and music allows us to link them both to symbolism and anti-modernism. Thus, it is possible to identify an evolution in their poetic works, in parallel to their lives.
\end{abstract}

Keywords: Unamuno, Borges, Poetry, Music, Modernism.

Son numerosos los estudios que relacionan la obra y pensamiento de Jorge Luis Borges y de Miguel de Unamuno. ${ }^{1}$ Ambos autores, voces canónicas de la literatura en español, comparten rasgos en sus biografías: atravesaron vivencias trágicas y profundas crisis existenciales; se interesaron por el discurso filosófico; renegaron del estilo literario que los precedió; presentaron una estética original y rupturista; mostraron posturas controversiales en el ámbito político, hecho que les negó la obtención del Premio Nobel de Literatura (a Unamuno, en 1935, a Borges, en 1976). Sin embargo, Borges también se ha mostrado en las antípodas del pensamiento unamuniano, al criticar su obra Vida de Don Quijote y Sancho (1905) por su estilo efusivo y sus “azarosas exornaciones” (Borges, 1996, p. 248). El amor por el género lírico fue, sin duda, algo que los unió. Este aspecto fue quizás más reconocido en torno al escritor argentino. Del otro lado, Unamuno 
se hizo popularmente conocido como escritor de novelas y ensayos filosóficos; sin embargo, él mismo admite que por encima de cualquier otra cosa se sentía poeta: “mucha de mi prosa no es más que verso abortado" (1958, X, p. 559).

En cuanto a la concepción musical ligada a la poesía, el Arte poética de Borges expresa que en la música es "imposible separar el sonido, la forma, y el contenido, pues son, en realidad, lo mismo. Y cabe sospechar que, en cierta medida, sucede lo mismo con la poesía" (2005, p. 102). El poema unamuniano que lleva el nombre de "Credo poético", en cambio, reza: “Algo que no es música es la poesía” (1958, XIII, p. 200). Parecería que sus concepciones musicales apuntan en direcciones opuestas, sin embargo, ahondaremos un poco más para verificar que ambas posturas coinciden.

La relación de Borges con la música parece más obvia que la de Unamuno si nos abocamos a lo que plantea Ana Lucía Frega, para quien la obra borgeana "rezuma música, es en y por la música" (2011, p. 14). Borges no fue músico en sentido profesional, pero para esta autora, conocía las relaciones ancestralmente exploradas entre la palabra y la música y las integró en su microcosmos (2011, p. 99). La doctora en música y estudiosa de la obra borgeana analiza la relación y la comprensión perceptiva del autor argentino para con la música, o mejor dicho, las músicas, por la variedad de géneros y estilos que se manifiestan en sus textos. Pero aquí nos enfocaremos en la concepción que estos autores tienen de la música en relación con la literatura, y específicamente, con su poesía. Para ello, es importante considerar el contexto histórico-literario en el que se inscribe su obra. Desde el plano de la interdiscursividad, nos preguntamos iqué concepción poética tienen de la música, o mejor aún, qué concepción musical tienen de la poesía?

\section{EL MODERNISMO Y LAS PARADOJAS}

Mucho se ha dicho acerca de las paradojas presentes en el pensamiento de Miguel de Unamuno. Su expreso rechazo a ser catalogado no impidió que se hablara y se escribiera acerca de las contradicciones de sus ideas. En especial la poesía fue su género más criticado. Para Rubén Darío, "los verdugos del encasillado" no comprendían que Unamuno hiciera tantas cosas: "a mi entender, Miguel de Unamuno es ante todo un

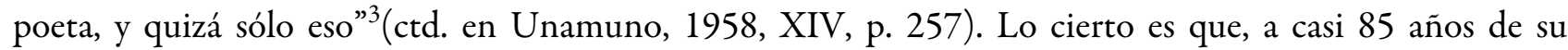
muerte, existen voces críticas que siguen intentando rescatarlo del pantano en que lo han sumergido y que lo ha estancado en una posición equívoca.

Una de las grandes discusiones sobre su poesía es si Unamuno ha sido en realidad un poeta simbolista o si, por el contrario, contradecía el contexto modernista en el que se hallaba. El artículo "Unamuno, poeta simbolista" de María Pilar Celma Valero, se refiere específicamente al uso de la métrica y la rima en la obra poética del escritor bilbaíno. La autora parte de una supuesta contradicción en el pensamiento de Unamuno, quien en su "Credo poético" atenta contra la música, pero luego adhiere a la teoría de las Correspondencias de Baudelaire, cuando afirma que el universo visible es una metáfora del alma (Celma Valero, 2002). En coincidencia con este pensamiento, dice Borges en "Vindicación de la poesía" que "la poesía (como la música) es el inmediato lenguaje del Espíritu” (Borges, 2011, p. 130). Lo cierto es que, como buen conocedor de los poetas ingleses, Unamuno "se apropia del modernism anglosajón de Joyce, Pound y Eliot con su profunda carga crítica procedente de una relectura moderna del romanticismo de Keats a Coleridge" (Ferrari, 2014, p. 22). Es así como él encarna en España una nueva vertiente del modernismo, que hace hincapié en el aspecto meditativo de la poesía, línea estética alejada del simbolismo de raíz francesa. ${ }^{4}$

El mayor error se presenta al separar las frases de su contexto. Lo expresa mejor el mismo Unamuno en su ensayo "Civilización y cultura": "Yo y el mundo nos hacemos mutuamente" (1958, III, p. 472). Al atravesar tantos años, es lógico que la obra poética del autor refleje cierta evolución; algo que, por cierto, ningún crítico literario debería obviar. En este sentido Francisco Ynduráin, estudioso de la poesía de Unamuno, 
argumenta: "La reacción antirromántica y antimodernista no deben desorientarnos, pues su poesía se hará más esencialmente musical con el paso del tiempo, irá perdiendo dureza y aristas” (1969, p. 112).

A pesar de la supuesta contradicción del autor estudiado, es necesario ubicar su poética en el contexto histórico-literario del modernismo español. Las voces de Rubén Darío y de Antonio Machado permiten despegarnos de cualquier juicio subjetivo:

Los gestos de protesta, de rebeldía, de iconoclasticismo, de injusticia, si queréis, que tanto asustan y escandalizan a unos cuantos pobres de espíritu ¿qué son en el fondo sino ese noble deseo de renovación? En todo esto que digo cabe mucha gloria a Miguel de Unamuno (Machado, 1905 en Celma Valero, 2002, p. 99).

La cita anterior evidencia que la disconformidad de Unamuno es la misma que la de los otros modernistas y simbolistas. Tras su crisis espiritual y los inevitables interrogantes de carácter existencial, Unamuno adoptó una actitud idealista en la que coincide con los modernistas. Por su parte, Rubén Darío concuerda con Unamuno en que el arte es un modo de vencer el tiempo y el espacio. Y es que para el escritor noventayochista el arte también vence la lógica, algo que es apreciable en sus paradojas constantes. Es necesario acudir a las citas directas de sus poemas y a otras voces autorizadas, como las de escritores contemporáneos a él: "Hay una música ideal como hay una música verbal. No hay escuelas; hay poetas. El verdadero artista comprende todas las maneras y halla la belleza bajo todas las formas. Toda la gloria y toda la eternidad están en nuestra conciencia" (Darío, [1907] 1980, p. 69). Estas palabras son del máximo exponente del modernismo literario $\mathrm{y}$, sin embargo, podrían haber sido dichas por Unamuno, pues expresan sus propias ideas.

A pesar de la crítica hecha por el autor bilbaíno a algunos poetas de su época que imitan el sonsonete, también ha sido capaz de desarrollar otros testimonios en favor de la musicalidad de la poesía. El mismo Rubén Darío describe a Unamuno como “amigo de paradojas” (en Unamuno, 1958, XIV, p. 257). Sin embargo, Unamuno reflexiona sobre el sentido de la música cuando la polémica en torno al modernismo ya se ha superado, de ahí la importancia de tener en cuenta el contexto. Del otro lado del Atlántico, la concepción borgeana resulta similar al decir en Historia de la eternidad (1936): "No en cuanto es melodía, pero sí en cuanto es Armonía y es Ritmo, la Música está ahí” (1989, I, p. 358). Borges también criticó el estilo modernista de algunos de sus contemporáneos, hecho que se evidencia en su manifiesto ultraísta (1921), en el que se postula en contra de todos los datos adicionales que disfrazan la emoción del poema, como la rima y la adjetivación excesiva usada por aquéllos. En cambio, incita a optar por la palabra concisa, por el vocabulario amplio pero preciso. Además de sostener a la metáfora como baluarte, su valoración de la música como complemento de la palabra lo llevó a criticar la poesía de Leopoldo Lugones, considerado el sucesor de Rubén Darío: "Mencionar los sonetos cometidos por el doctor Lugones, equivale a medirlos mal para siempre, a refutar cada una de sus metáforas [...] pero los sonetos quedan también, con música que espera” (Borges, 1989, I, p. 420).

Tanto Borges como Unamuno se postularon contra la estética modernista pero desde un aspecto estilístico. Frega valida la elección de Borges al incluir el campo musical en su poesía: "Y no es solamente justificativo el tema de la versificación, del ritmo y del sentido: es la elección de qué se usa para dar cuenta de un entorno, de una realidad, del momento infinitamente único" (Frega, 2011, p. 62). Y es que la adecuación de la música al sentido del poema no está muy alejada del imaginario musical de Verlaine, Baudelaire y Mallarmé, poetas admirados por Borges, para quien la magia de las palabras reside en su musicalidad (Borges, 2005).

\section{EL SIMBOLISMO Y LA ARMONÍA}

Dentro del contexto modernista en que vivió Unamuno, Celma Valero apuesta por incluirlo en la línea del pensamiento simbolista, a pesar de que muchos lo hayan separado de este y que incluso el mismo Unamuno haya escrito aquella frase que fue su máxima expresión contra el simbolismo y que expusimos al comienzo de este artículo. Al buscar una mayor objetividad que rescate al escritor de los encasillamientos 
que le ha otorgado la crítica general, la autora explica la concepción poético-musical de Unamuno, para quien la musicalidad debe sumergirnos en nuestra propia conciencia y llevarnos a lo trascendente (concepción semejante, primero, a la de Fray Luis de León, y luego, como se ha dicho, a la teoría simbolista de las Correspondencias). Francisco Ynduráin (1969) habla del ritmo generador de la poesía unamuniana, que es el ritmo formal que debe estar en perfecta armonía con el contenido del poema, porque deriva de la conciencia del poeta. En la misma línea, Borges concibe a la música como "el arte en que la forma es el fondo" (1989, I, p. 249).

La poesía de Unamuno está llena de símbolos, recurso explotado por el poeta debido a que siente una insuficiencia de las palabras para poder expresarse. Borges, por su parte, sostiene: "Ya no creo en la expresión, solo creo en la alusión. Después de todo, ¿qué son las palabras? Las palabras son símbolos para recuerdos compartidos" (2005, p. 140). Pero lo que hay que tener en cuenta es que el simbolismo no reside tanto en lo material, como en su concepción de la poesía y del poeta. Los mismos simbolistas diferían en la concepción que tenían de la musicalidad; así, el pensamiento de Unamuno estaría más cerca de lo planteado por Baudelaire, para quien las palabras y las notas musicales guardan la misma propiedad sugerente. El poeta francés planteó la búsqueda del valor sonoro de la palabra en la creación poética. En esta misma línea, Borges conocía y admiraba el sonido de la palabra, y su decir "enhebra y refuerza su sentido, sin extremismos, moderadamente y en búsqueda permanente de equilibrio musical” (Frega, 2011, p. 52). Prueba de ello es la manera en que, en varios de sus textos, da cuenta de la musicalidad de los idiomas: ${ }^{6}$

ese color que resplandece en la poesía y que tiene tan lindos nombres en muchos idiomas. Pensemos en scharlach, en alemán, en scarlet, en inglés, escarlata en español, écarlate, en francés. [...] Palabras que parecen dignas de ese gran color. En cambio, "amarillo" suena débil en español; yellow en inglés, que se parece tanto a amarillo [...] Por eso los versos en un idioma extranjero tienen un prestigio que no tienen en el idioma propio, porque se oye, porque se ve cada una de las palabras: pensamos en la belleza, en la fuerza, o simplemente en lo extraño de ellas (Borges, 1989, III, pp. 277-280).

Como establecemos en los ejemplos dados, la musicalidad buscada no es exclusiva del género lírico, aunque indudablemente está ligada a él y es justamente la poesía el género en que nos basamos para analizar la concepción musical que tienen ambos autores. Vemos así cierta conciencia y agudeza en la elección de la palabra por su sentido de la sonoridad, uniendo en su discurso el significado conceptual y expresión auditiva.

\section{INTERDISCURSIVIDAD: LA PALABRA MUSICAL}

A la hora de hablar de la concepción musical que hay en la poesía de Unamuno, es necesario recurrir a sus propios textos, y es así como hacemos hincapié en el ya citado "Credo poético" y en el poema "Música", que desde el primer verso atentan contra el "Artpoétique" de Verlaine y su "de la musique avant toute chose". Lo que Unamuno busca es que la poesía sea expresión en libertad del pensamiento y del sentimiento, que el poema surja "a partir de la meditación sobre una experiencia emocional previa, filtrada por el tamiz intelectivo" (Ferrari, 2014, p. 18). Si bien no es el pensamiento el que impone un ritmo, lo que el autor bilbaíno busca es una musicalidad que no dependa de factores externos, sino que para él el ritmo debe venir de dentro, de la armonía del poema, por eso se niega a caer en estructuras y formalismos. En la misma línea, para Frega, "Borges eligió sentido propio musical, no cantidad de sílabas o justeza de rima" (2011, p. 90).

Como destaca Celma Valero, Unamuno no se opone ni a la métrica ni a la musicalidad en sí, sino que busca que cumplan una función, es decir que no limiten el pensamiento, lo cual en verdad es revalorizar el verdadero sentido de la musicalidad del verso (Celma Valero, 2002). De la misma manera -y en concordancia con la poética modernista- prefiere la rima asonante a la consonante que limita la libertad creadora. Cabe destacar también que hay excepciones a este rechazo, como en varios de los poemas del Rosario de sonetos líricos (1911) o en el siguiente ejemplo del Cancionero (1953): 


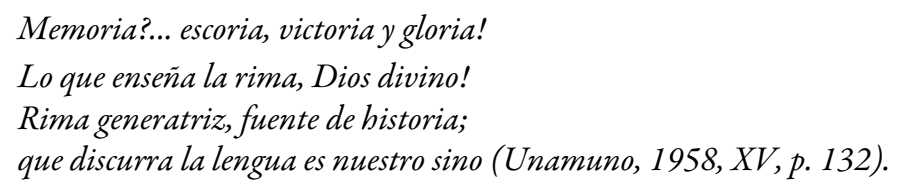

En el marco de los estudios músico-literarios, nos encontramos en el campo de la música en la literatura, y dentro de dicha área estamos ante lo que Steven Paul Scher denomina "verbal music", es decir, literatura que trata sobre música (1982, p. 237). El ejemplo expuesto no solo es una de las muchas excepciones del rechazo a la rima consonante, sino que en el mismo poema habla del poder evocador de la rima. Otro ejemplo lo encontramos en el soneto "A la rima" en el que se refiere a esta como "Macizas ruedas en pesado carro" (Unamuno, 1958, XIII, p. 463), pero en el que no abandona la forma del soneto clásico.

Cabe destacar la voluntad de Celma Valero de alejar a Unamuno de los extremos en que los ha puesto con frecuencia la crítica. Unamuno no se aleja de la corriente modernista de su época, de los escritores que lo rodean, pero tiene un pensamiento individual y original a la vez. Este equilibrio es lo que buscamos rescatar, para adscribir la poesía de Unamuno al simbolismo francés, a través de su concepción de la musicalidad. Entonces, si la base de la poética unamuniana confluye con un principio del simbolismo, ¿cómo puede oponerse a este? La respuesta la hallamos en que Unamuno cambiaba de pensamientos de acuerdo a sus vivencias y sentimientos. La experiencia cercana de la muerte lo ha envuelto en una serie de contradicciones: buscaba la fe negando a Dios, añoraba ser inmortal sabiéndose finito, amaba la esencia de la música pero rechazaba la musicalidad externa en la poesía. ¿Poeta simbolista? ¿Poeta antimodernista? Hemos intentado rescatarlo de algunos pantanos en que lo han sumergido (en que se ha sumergido él mismo), la pregunta que nos queda es si él mismo quería ser rescatado. Basta con que nos queden sus textos, ideas y pensamientos.

En su novela Niebla, Augusto Pérez le reclama a Miguel de Unamuno personaje: "No quiere usted dejarme ser yo, salir de la niebla, vivir, vivir, vivir, verme, oírme, tocarme, sentirme, dolerme, serme” (Unamuno, 1958, II, p. 982). En una coherente preocupación por la autenticidad del ser, hemos de decir que para Unamuno lo que hace que seamos más nosotros mismos es una profundización en el sentido de la verdadera música. De esta manera, sus ideas sobre la poesía y la música -y sobre la vida- no resultan tan paradójicas, ni tan alejadas de su contexto. "El poeta de nuestro tiempo no puede dar la espalda a su tiempo", dice el personaje del cuento "El otro" de Borges. Casualmente, dicho personaje está escribiendo un libro llamado Los himnos rojos, ante lo cual el narrador le recomienda considerar "el verso azul de Rubén Darío y la canción gris de Verlaine" (Borges, 1989, III, p. 14). Vemos así como sus ideas musicales se vuelcan también en su prosa. Por eso Frega sostiene que el microcosmos pluri-lenguaje de Borges "se constituyó incluyendo la música como uno de sus elementos expresos válidos. Conscientemente” (2011, p. 88).

Dejando de lado la ilusión de conformar una visión total y absoluta, analizar el pensamiento de estos dos grandes autores de la literatura en español desde lo musical permite ampliar el conocimiento de su obra desde un campo menos atendido, poner en duda las aparentes contradicciones de Unamuno, estrechar las diferencias existentes entre ambos autores, y dejar una puerta abierta para el estudio intermedial.

Para Unamuno, "la poesía es obra abierta, hecha para meditar, para reflexionar -que es reflejar en los espacios/espejos interiores" (Blasco Pascual, Celma Valero y González, 2003, p. 28). Con respecto al significado borgeano del término música, Frega acude a una cita de Julien Green: "La música dice frecuentemente lo que se debe decir porque dice lo que jamás la palabra ha podido expresar y a través del ruido maravilloso que hace, atrae el silencio" (Frega, 2011, p. 28). Los pensamientos de ambos autores se unen en los conceptos mencionados (meditar, reflexionar, interior, decir, silencio) y en que ambos creyeron indudablemente en la relación necesaria entre la palabra justa y la palabra musical.

\section{ReFERENCIAS}

Blasco Pascual, F. J., Celma Valero, M. P. y González, J. R. (2003). Miguel de Unamuno, poeta. Valladolid: Secretariado de Publicaciones e Intercambio Editorial, Universidad de Valladolid. 
Borges, J. L. (1989). Obras completas (tomos I y III). Barcelona: Emecé.

Borges, J. L. (1996). Obras completas (tomo IV). Barcelona: Emecé.

Borges, J. L. (2005). Arte poética. Seis conferencias. Barcelona: Colección Biblioteca de Bolsillo.

Borges, J. L. (2011). Textos recobrados 1956-1986. Buenos Aires: Sudamericana.

Celma Valero, M. P. (2002). Miguel de Unamuno, poeta simbolista. Anales de literatura española, 15, 93-107. doi: h ttps://doi.org/10.14198/ALEUA.2002.15.06

Darío, R. ([1907] 1980). Dilucidaciones. En R. Gullón (Ed.), El modernismo visto por los modernistas (pp. 57-69). Barcelona: Guadarrama.

Ferrari, Marta B. (2014). Unamuno: Obrero del pensamiento. Villa María: EDUVIM.

Frega, A. L. (2011). Borges y la música. Buenos Aires: Editorial SB.

Iwasaki Cauti, F. (2010). Borges, Unamuno y el “Quijote”. Biblioteca Virtual Miguel de Cervantes. Edición digital a partir de Hueso Húmero, 50 (2007), 78-89. Recuperado de http://www.cervantesvirtual.com/obra-visor/borg es-unamuno-y-el-quijote/html/bad43be2-4722-4e88-86ee-ea3b48061d5a_5.html

Koch, D. M. (junio 1984). Borges y Unamuno: Convergencias y divergencias. Cuadernos Hispanoamericanos, 408, 113-122. Recuperado de http://www.cervantesvirtual.com/nd/ark:/59851/bmczk5x2

Robles, L. (Ed.). (1987). Epistolario completo Ortega-Unamuno. Madrid: El Arquero.

Scher, S. P. (1982). Literature and Music. In Jean-Pierre Barricelli and Joseph Gibaldi (Eds.), Interrelations of Literature (pp. 225-250). New York: MLA.

Serrano, C. (2004). XIV. Duplicaciones y duplicidades. Unamuno autor de Pierre Ménard. En Miguel de Unamuno. Entre histoire et littérature (pp. 269-276). Paris: Presses Sorbonne Nouvelle.

Unamuno, M. de (1958). Obras completas (tomos II, III, X, XIII, XIV, XV). Ed. Manuel García Blanco. Madrid: Afrodisio Aguado.

Ynduráin, F. (1969). Unamuno en su poética y como poeta. En Clásicos modernos. Estudios de crítica literaria (pp. 59-125). Madrid: Gredos.

\section{NoTAS}

1 Algunos ejemplos de estudios que relacionan la obra de ambos autores son: Koch, D. M. (1984). Serrano, C. (2004). Iwasaki Cauti, F. (2010).

2 Deseo que se hace explícito en una carta enviada a Ortega y Gasset en 1912, donde dice: "Tengo la flaqueza de creer que o soy poeta o no soy nada. Ni de filósofo, ni de pensador, ni de erudito, ni de filólogo me precio; sólo presumo de ser un buen catedrático y un sentidor o un poeta" (Robles, 1987, p. 104).

3 Palabras de Rubén Darío publicadas en La Nación, Buenos Aires, el 2 de mayo de 1909, bajo el título de "Unamuno, poeta". El texto fue posteriormente incluido en el prólogo de Teresa.Rimas de un poeta desconocido (1924).

4 Jordi Doce, en su estudio Imán y Desafío. Presencia del romanticismo inglés en la poesía española contemporánea, habla de la relación entre la poesía meditativa de Unamuno y la poesía inglesa, desde los musings de Wordsworth y Coleridge a los Cuartetos de Eliot. Este trabajo es retomado por Marta Ferrari (2014) en el estudio preliminar y antología poética, citados en este artículo.

5 "El cantar es casi una idée fixe [...] en la creación de este poeta. O un hilo conductor/leit motiv. La poesía y la música. La poesía, el paisaje, la música. Entrelazamiento simple y complejo a la vez. Precisión y riqueza expresiva. La sonorización que da forma a la metáfora: la fuerza para describir un paisaje/sentimiento [...] Y no es falta de vocabulario el reiterado uso de la familia de palabras de canto/cantar: es que permite unir la indisolublemente histórica relación palabra/melodía. Es el decir inicial, primigenio, la palabra creadora devenida música” (Frega, 2011, pp. 60, 62).

6 Uno de los textos donde se hallan reflexiones sobre el valor sonoro de los idiomas es su ensayo sobre "La ceguera", en el que cuenta cómo al quedarse ciego "había reemplazado el mundo visible por el mundo auditivo del idioma anglosajón" (Borges, 1989, III, p. 280). Más ejemplos pueden encontrarse en el prólogo a La moneda de hierro: "La música de hierro del sajón no nos place menos que las delicadezas morosas del simbolismo” (Borges, 1989, III, p. 121). También en su conferencia "Credo de poeta", incluida en Arte poética: "El hecho de que muchos de ustedes no sepan español mejorará el soneto. Como he dicho, el significado no es importante: lo que importa es cierta música, cierta manera de decir las cosas. Quizá, incluso si la música falta, ustedes la sientan” (Borges, 2005, p. 144). 